APORTACIÓN AL ESTUDIO DE EL GRECO POR INVESTIGADORES VINCULADOS AL CSIC / CONTRIBUTION TO THE STUDY OF EL GRECO BY RESEARCHERS LINKED TO THE CSIC

\section{NUEVOS CAMPOS ABIERTOS A LA INVESTIGACIÓN A PARTIR DE ALGUNAS EXPOSICIONES DEDICADAS A LA OBRA DE EL GRECO}

\author{
Isabel Mateo Gómez \\ Consejo Superior de Investigaciones Científicas \\ isabelmateogomez@hotmail.com
}

\begin{abstract}
Cómo citar este artículo/Citation: Mateo Gómez, I. (2015). "Nuevos campos abiertos a la investigación a partir de algunas exposiciones dedicadas a la obra de El Greco". Arbor, 191 (776):
\end{abstract} a279. doi: http://dx.doi.org/10.3989/arbor.2015.776n6006

Recibido: 22 diciembre 2014. Aceptado: 9 marzo 2015.

RESUMEN: Antes de que en 1579 El Greco pintara El Expolio, un pintor toledano, Juan Correa de Vivar, había interpretado este tema cuatro veces, en las décadas de los cuarenta, cincuenta y sesenta. Las anomalías iconográficas del tema respecto a los Evangelios Canónicos, que aparecen ya en las composiciones de Correa, están inspiradas en la literatura mística medieval, ligada a la Orden Cisterciense.

PALABRAS CLAVE: exposiciones; Toledo; El expolio; literatura mística medieval.

\section{NEW FIELDS OF RESEARCH OPENED UP BY EXHIBITIONS OF EL GRECO'S WORK}

Copyright: (C) 2015 CSIC. Este es un artículo de acceso abierto distribuido bajo los términos de la licencia Creative Commons Attribution-Non Commercial (by-nc) Spain 3.0.
ABSTRACT: Before 1579, the year in which El Greco painted El expolio, a painter from Toledo, Juan Correa de Vivar, had depicted this subject four times in the 40s, 50s and 60s. The iconographic anomalies of the subject with regard to Canonical Gospels, which appear in Correa's compositions, stem from medieval mystical literature, related to the Cistercian Order.

KEYWORDS: exhibitions; Toledo; El expolio; medieval mystical literature. 
La bibliografía sobre El Greco -abundantísimaabarca los diversos aspectos de su singular adaptación al manierismo, de su color, de su luz y de sus modelos, tanto en su obra religiosa como profana. Toda esta bibliografía ha sido sintetizada y enriquecida por José Álvarez Lopera en su magnífica obra El Greco. Estudio y catálogo (2007).

Todas las aportaciones que los historiadores y críticos han dado sobre El Greco, han abierto nuevos caminos de investigación sobre el pintor cretense, pero hay que resaltar el papel que las exposiciones han jugado en este sentido. ¿Qué es o que se propone una exposición? ¿Se trata únicamente de la presentación de "obras" para ser vistas por el público, o se trata de que, a través de ella se ponga sobre la mesa los problemas existentes sobre el artista y su obra? Cuando se decide hacer una exposición, sin duda se tiene en cuenta el "momento" en que se decide llevarla a cabo y, entre ellos, habría que destacar el sacar del olvido al artista, reivindicando su valor, o celebrar un acontecimiento relacionado con él, por ejemplo un centenario. La primera y última exposiciones monográficas sobre El Greco - 1902 y 2014 - responden a cada uno de estos motivos.

El éxito de una exposición está sujeto a muchos factores, quizás, el más importante, el propósito del Comisario cuando la lleva a cabo, la calidad de las obras y el entorno histórico-artístico en que se produjeron. Todo ello servirá para desglosar aspectos inéditos del artista y su obra, y la comunicación de conocimientos con un valor científico final.

Centrándonos en El Greco, nuestra época romántica no sintió especial atracción por él. Curiosamente fueron las "vanguardias" quienes hallaron en él atractivos valores que hicieron suyos. De este tema existen interesantes trabajos de Álvarez Lopera (1995), de Brunno Bandini (1995), de E. Foundoulaki (1995), y su interés ha sido recogido en una sugerente exposición celebrada en año 2014 en el Prado, al conmemorarse el V Centenario de la muerte del pintor, con el título EI Greco y la Modernidad ${ }^{1}$.

La primera exposición monográfica de El Greco se celebró en el Prado en el año 1902. Se trató de una pequeña exposición y catálogo, cuyo texto está escrito por el subdirector y conservador del museo, don Salvador Viniegra. De todo lo recogido en este pequeño catálogo, destacaremos la definición espiritual que el autor hace de El Greco como buscador en el "más allá de la perfección", mezclando la ascética y el realismo en sus obras. También la reproducción por primera vez, de un San Roque (fig. 1), de la colección de Carmen Mendieta, de pequeño tamaño $0,43 \times 0,37$, de medio cuerpo, que actualmente se encuentra en la Hispanic Society de Nueva York, recogido en la obra de Wethey (1967) como interesante copia de escuela².

Figura 1. El Greco. San Roque. Hispanic Society, Nueva York

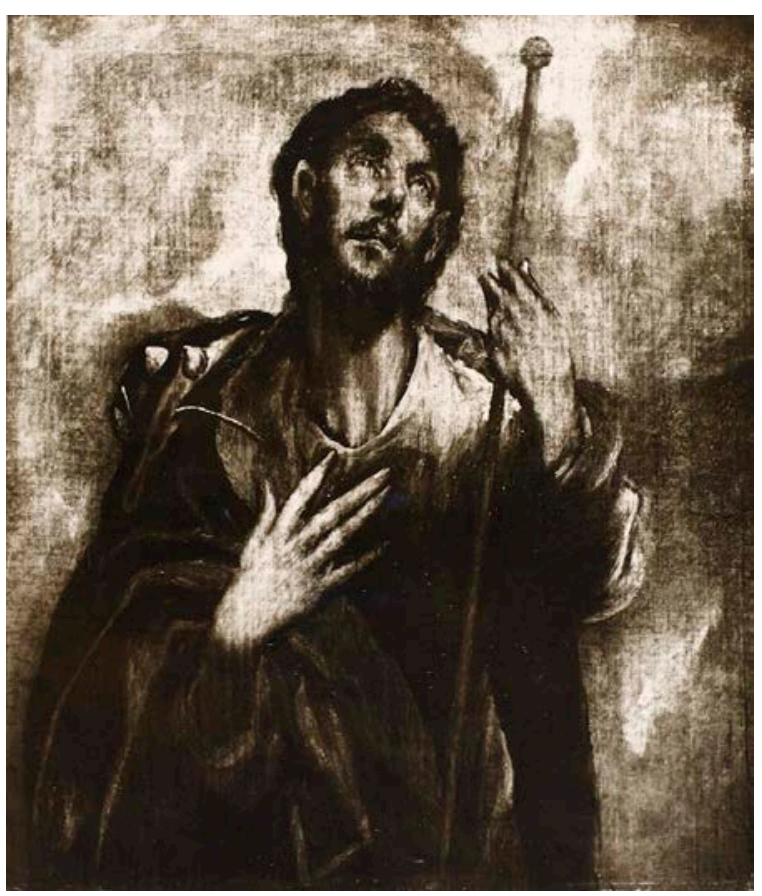

Muchas han sido las exposiciones sobre el cretense, desde la pequeña de 1902. A algunas de ellas nos referiremos luego, por su diferente propósito de exhibición. Queremos destacar la recientemente celebrada en Toledo, con motivo del V Centenario. Su comisario, Fernando Marías, ha revestido Toledo con toda la pintura de El Greco, desgraciadamente dispersa por el mundo, reuniendo y componiendo retablos, que la desamortización había sacado de los conventos. En una palabra, ninguna celebración mejor, ni mejor recuerdo para el pintor, que ver "recolocada" su obra, en la Capilla de San José y en el espléndido espacio del museo de Santa Cruz de Toledo. La exposición, El Griego de Toledo, ha cumplido todos sus propósitos y perspectivas científicas e iconográficas. La Capilla de San José representa en su más alto nivel la devoción que por el santo sintió la capital toledana de la segunda mitad del siglo XVI, no en vano fue el toledano don Francisco Villegas el que recitó la oración fúnebre a la muerte de Santa Teresa, y quien escribió - además de una nueva 
versión discutida de la Celestina - un Flos Santorum, libro que se encontraba en la biblioteca de El Greco, biblioteca estudiada por Javier Docampo en otra exposición del $\mathrm{V}$ Centenario de la muerte del pintor. En las bibliotecas se hallaban libros al uso del artista, pero, también, se dejaban asesorar por sus comitentes, quienes, en muchos casos, tenían mejores bibliotecas que ponían a disposición del artista.

Entre la primera exposición de 1902 y la de su reciente Centenario, en Toledo, se han celebrado otras, algunas con distinto propósito, especialmente las que tuvieron lugar en 1982. Una de ellas, El Greco de Toledo (Brown et al., 1982), fue fruto de numerosos esfuerzos individuales y colectivos - como señaló Javier Tussell, en el prólogo del Catálogo - encaminada al estudio y valoración de uno de los más grandes pintores de nuestro pasado. En ella se conjugaron los valores estéticos y el carácter científico, y puede considerarse - sin duda - un precedente de la del 2014 en Toledo. La idea de su celebración surgió en 1978 - fecha que coincide con la llegada de El Greco a la ciudad Imperial - en el Toledo Museum of Art (Ohio). Al acontecimiento se unieron la National Gallery de Washington, quien publicó las ponencias del congreso que acompañaron a la exposición ${ }^{3}$, el Museo de Bellas Artes de Dallas (Texas) y el Museo del Prado, estableciéndose entre ellos una generosa colaboración. La exposición tuvo un gran valor emocional, ya que muchas obras habían salido de España a causa de la insuficiente ley de protección de nuestro patrimonio. Este valor emocional lo hemos vuelto a percibir en el reciente Centenario.

En el catálogo de 1982 intervinieron J. Brown, W. Jordan y Alfonso E. Pérez Sánchez, quienes aportaron novedades histórico-artísticas fundamentales, bajo la dirección del profesor J. M. Pita Andrade, Comisario de la exposición en España. Uno de los estudios a destacar por su interés era "El Greco disperso", elaborado por Pérez Sánchez.

Paralelamente a la exposición de El Greco de Toledo que se celebraba en el Prado, el profesor Pérez Sánchez organizó en el Hospital Tavera e Iglesia de San Pedro Mártir, de Toledo, otra exposición con el título El Toledo de El Greco, en la que se abordaba y sacaba a la luz el panorama artístico toledano que el cretense encontró a su llegada a la ciudad, y su relación con él. Pero se consiguió algo más, salieron a relucir pintores toledanos poco conocidos y se diferenciaron pintores que hasta ese momento sus obras habían estado atribuidas a uno solo, y obras dadas por destruidas y desaparecidas en 1936, vieron la luz y brillaron gracias a una buena restauración.
Respecto a la vinculación y estima de El Greco hacia estos pintores toledanos, una parte de la crítica defiende el aislamiento del pintor respecto a su medio cultural y social, su independencia, así como la ausencia de discipulado. Tal vez esta parte de la crítica se viera influida por lo que Jusepe Martínez en sus Discursos, escribió sobre él "de extravagante condición y con gran estima de sí mismo" (Martínez, 1866/1988). La excelente labor llevada a cabo por el Profesor Pérez Sánchez en esta Exposición permitió puntualizar, hasta qué punto eran ciertas o falsas esas opiniones. Por otro lado, un hombre "intelectualmente" considerado, ¿cómo iba a rechazar la aportación de los pintores toledanos que habían trabajado para los cardenales y la nobleza de la diócesis? Ciertamente nuestra pintura del siglo XVI no estaba a la altura de la italiana (cf. Marías, 1989, pp. 610-631), pero la "curiosidad" y el "interés" para adaptarse a la clientela toledana pudieron ser estímulos "humanos" suficientes para un recién llegado y no con muy buenos comienzos admirativos hacia su obra.

Entre los pintores a destacar en Toledo se hallaban los Aguilar, Blas de Prado, Luis de Velasco y Correa de Vivar, fallecido este último pocos años antes de la llegada de El Greco, y pintor favorito de cardenales, nobles y órdenes religiosas, dentro y fuera de Toledo. Una de las obras más importantes realizadas por él es el Calvario con donantes - los canónigos don Bernardino de Alcaraz y don Juan Álvarez de Toledo - para la Capilla de los Cedillo, en la iglesia del Salvador de Toledo (fig. 2), y que pudo influir en la Crucifixión con donantes - más simplificada - que El Greco pintó para las Jerónimas de San Pablo, de Toledo, y que actualmente se halla en el Museo del Louvre (fig. 3). Esta concordancia fue expuesta en el Simposio celebrado en Toledo con motivo de la exposición El Toledo de El Greco, en 1982 (Mateo Gómez, 1982). Pérez Sánchez destacó el seguimiento que Luis de Velasco - sin ser discípulo de El Greco - hizo de sus modelos en el retablo de la Capilla de San Blas, de la catedral toledana, y en un Tránsito de la Virgen, que se conserva en el Museo de Santa Cruz de Toledo (Pérez Sánchez, 1982, p. 160), en el que convergen la composición del mismo tema, pintado por Correa de Vivar, en el Prado (fig. 4) y los modelos del cretense (fig. 5). Curiosamente, Luis de Velasco tasó en 1579 el Expolio de El Greco, cuatro veces por debajo del valor que había dado el cretense (Mateo Gómez y López-Yarto Elizalde, 2005, p. 280 y p. 305). 
Figura 2. Juan Correa de Vivar. Calvario con donantes. Iglesia del salvador, Capilla de los Cedillo, Toledo.

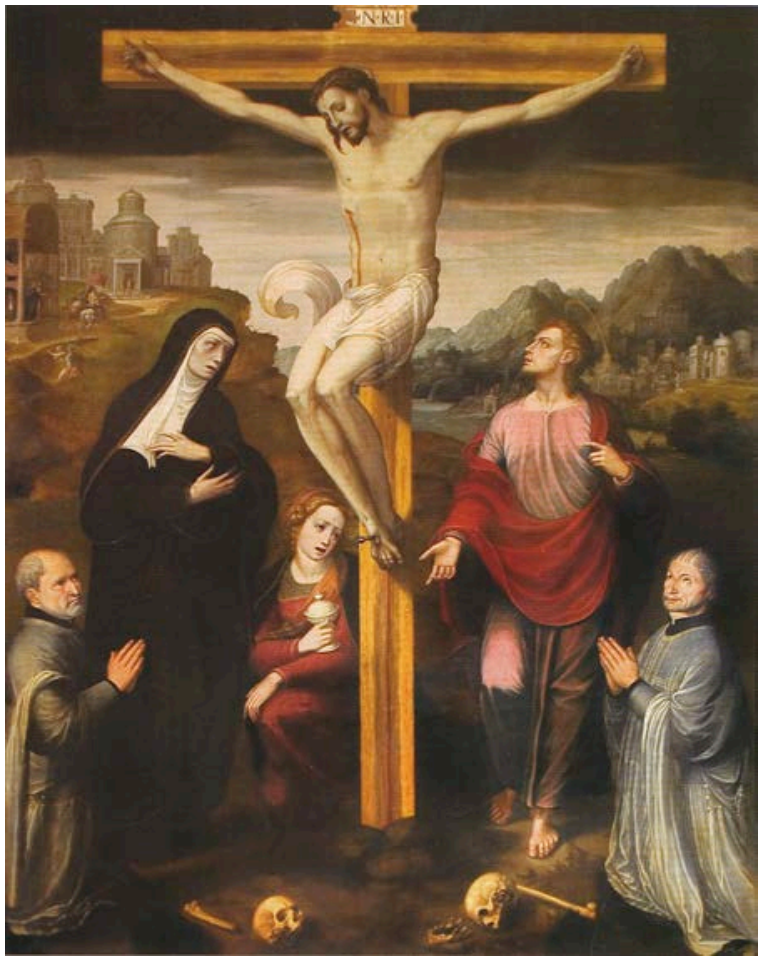

Figura 3. El Greco. Crucifixión con donantes. Museo del Louvre, Paris.

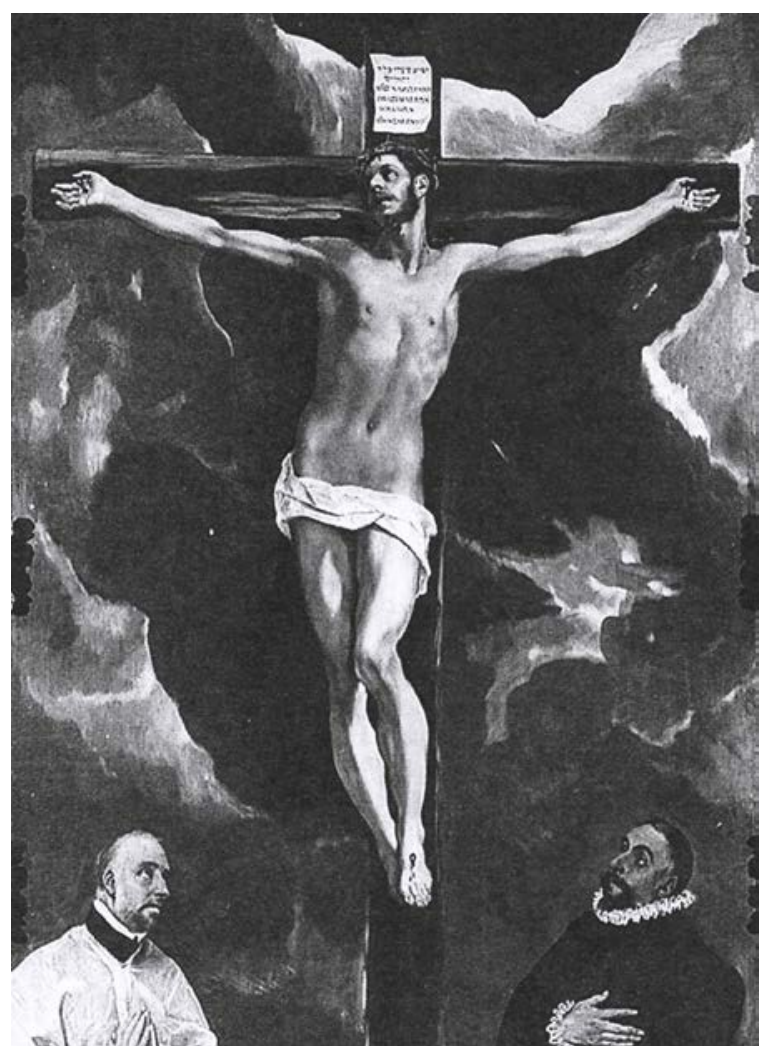

Figura 4. Juan Correa de Vivar. Tránsito de la Virgen. Museo del Prado, Madrid.

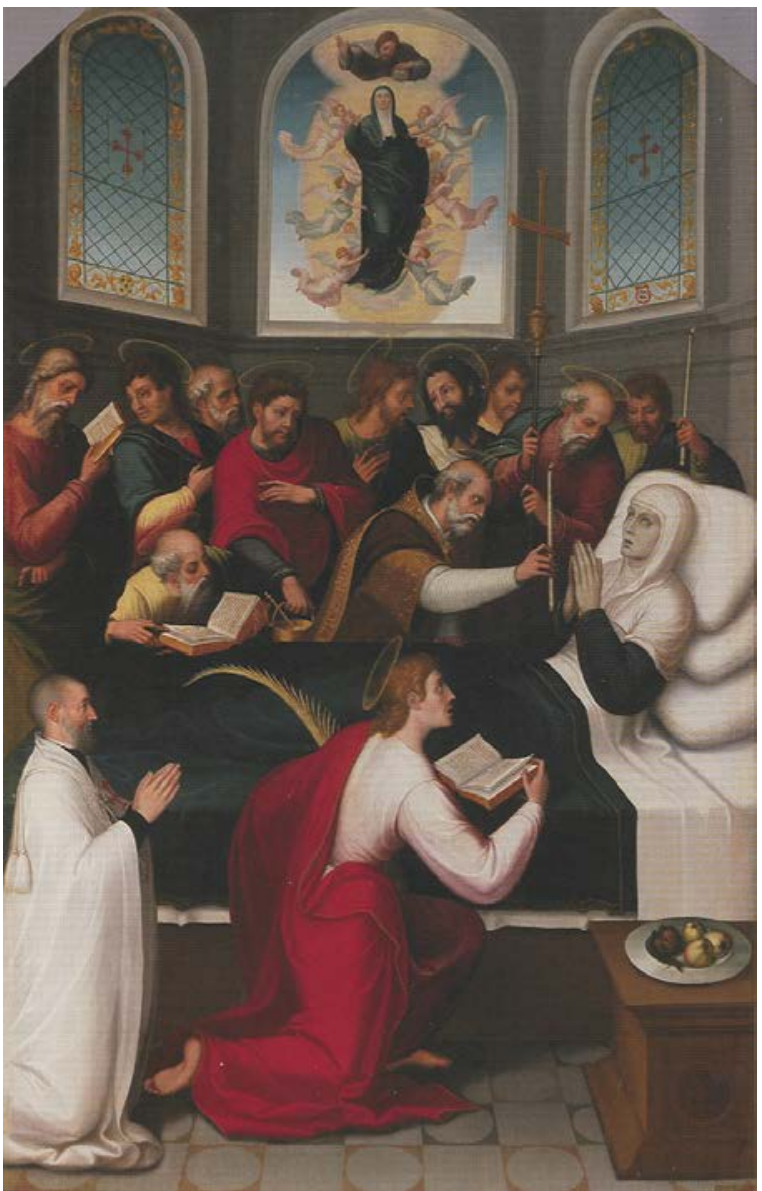

Figura 5. Luis de Velasco. Tránsito de la Virgen. Museo de Santa Cruz, Toledo.

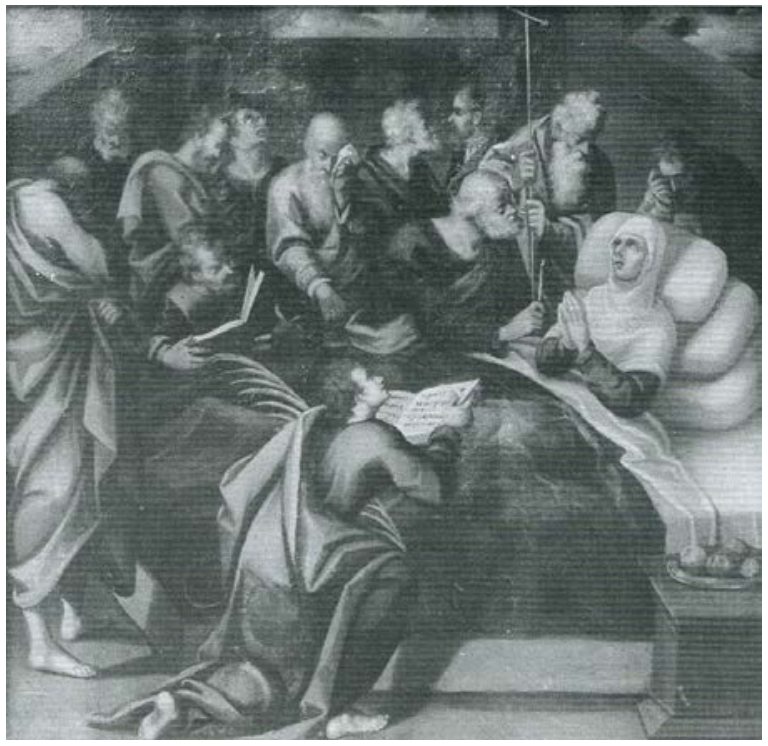


Recientemente se ha insistido en la influencia que los pintores toledanos pudieron tener en El Greco, especialmente en cuanto a lo referente a la iconografía, habida cuenta del fracaso del San Mauricio, para El Escorial, y de los "peros" que se le pusieron respecto al Expolio. Recordemos, además, que con El Greco colaboran en Santo Domingo el Antiguo artistas toledanos, entre ellos dos pintores vinculados a Juan Correa de Vivar, Hernando de Ávila y los Cisneros (Ceán Bermúdez, 1800; Mateo Gómez y LópezYarto Elizalde, 2005, pp. 56-91 y pp. 136-146).

Aunque el sentimiento religioso italiano fuera distinto al castellano, los autores que se han dedicado a este aspecto de El Greco, le consideran influido por el contexto místico de la ciudad. Ya Viniegra en el catálogo citado de 1902 define su obra como una mezcla de exaltación mística y naturalismo religioso. A este aspecto le ha dedicado muchas páginas David Davies (Davies, 1982, p. 57; Davies y Elliot, 2003, p. 45) y también A. Rodríguez Gutiérrez de Ceballos (1982, p. 153).

En el año 1579, Felipe II encarga a El Greco el cuadro de San Mauricio para presidir una de las capillas de la basílica de El Escorial (fig. 6). Sabemos que la forma de interpretar el tema por el cretense no fue del agrado del monarca, sin duda por hallarse lejos de sentimiento religioso exigido, por aquellos años, a un cuadro de devoción, expresado por el Padre Sigüenza así: "El cuadro tenía que ser de una gran simplicidad, Ilaneza histórico-didáctica, comprensible a todo el mundo..., para que convidara a rezar" (Sigüenza, 1903, libro I, c. XIV y libro II, c. XI).

La interpretación del tema del Expolio, que El Greco pintó para la sacristía de la catedral de Toledo, causó algunos problemas al pintor, puesto que el cabildo aspiraba a una reproducción fiel de los evangelios canónicos, que eran poco explícitos al describir este pasaje, limitándose a decir que "desnudaron a Cristo y le cubrieron con un paño púrpura". El Greco ha enriquecido el escueto texto, sumándole personajes que no aparecen en él y centrando la composición en la figura de Cristo, destacada sobremanera por el intenso manto púrpura que le cubre. Soldados con picas forman una galería al fondo y, delante de ellos, diversos personajes vestidos de armadura, a la moda del momento, sayones, y otro más al fondo que señala hacia el espectador, llamando su atención, con gorguera e indumentaria de la época. En la parte baja el pintor ha colocado, de medio cuerpo, presenciando la escena, a la Virgen y las Marías - no presentes en los evangelios canónicos - y a la derecha un sayón preparando la cruz.
Figura 6. El Greco. El Expolio. Museo del Prado, Madrid.

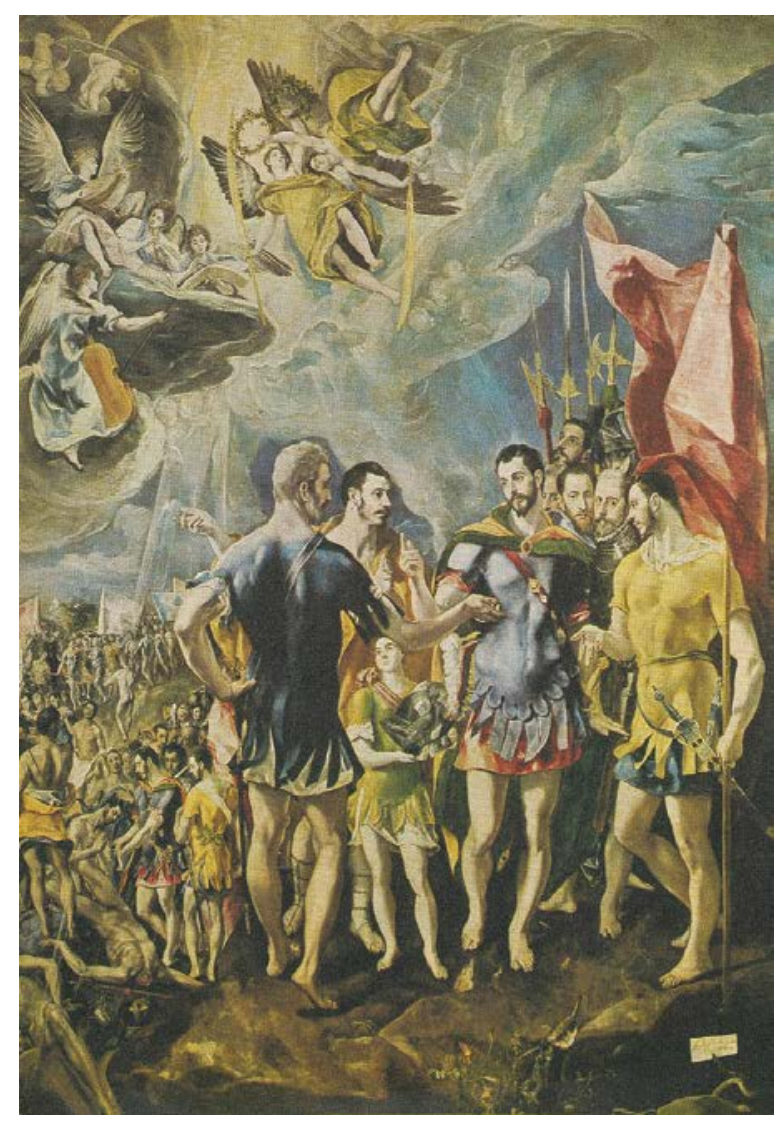

El profesor Azcárate (1955) sugirió como fuente inspiradora del tema del Expolio de El Greco, las Meditaciones de San Buenaventura: "Mira con cuidado todo lo que se hace contra tu Señor y todo lo que él mismo dice y hace..., ahora se desnuda, ahora la Madre ve por primera vez a su Hijo tan maltratado y dispuesto a ser atormentado con mortal dolor. Apodérase de ella una grandísima tristeza y rubor por verlo completamente desnudo, pues no le dejaron ni aún los paños de la honestidad... y envuelve su desnudez con el velo de la cabeza [de la Virgen]". Para el Cabildo la forma de representar el pasaje de El Greco "era impropio", pues no estaba bien visto en ese momento que las mujeres vieran a un hombre desnudo.

Azcárate se preguntó si existía alguna representación de este texto, aparte de las versiones que existen del $E x$ polio de El Greco, y Álvarez Lopera (1985) afirma "que el Greco carecía virtualmente de precedentes sobre el que apoyarse", debiendo haber echado mano de otros pasajes de la Pasión, como el Prendimiento y los Escarnios (v. 3, p. 12). Los historiadores, en general, han seguido 
Figura 7. El Greco. El Expolio. Catedral, sacristía, Toledo.

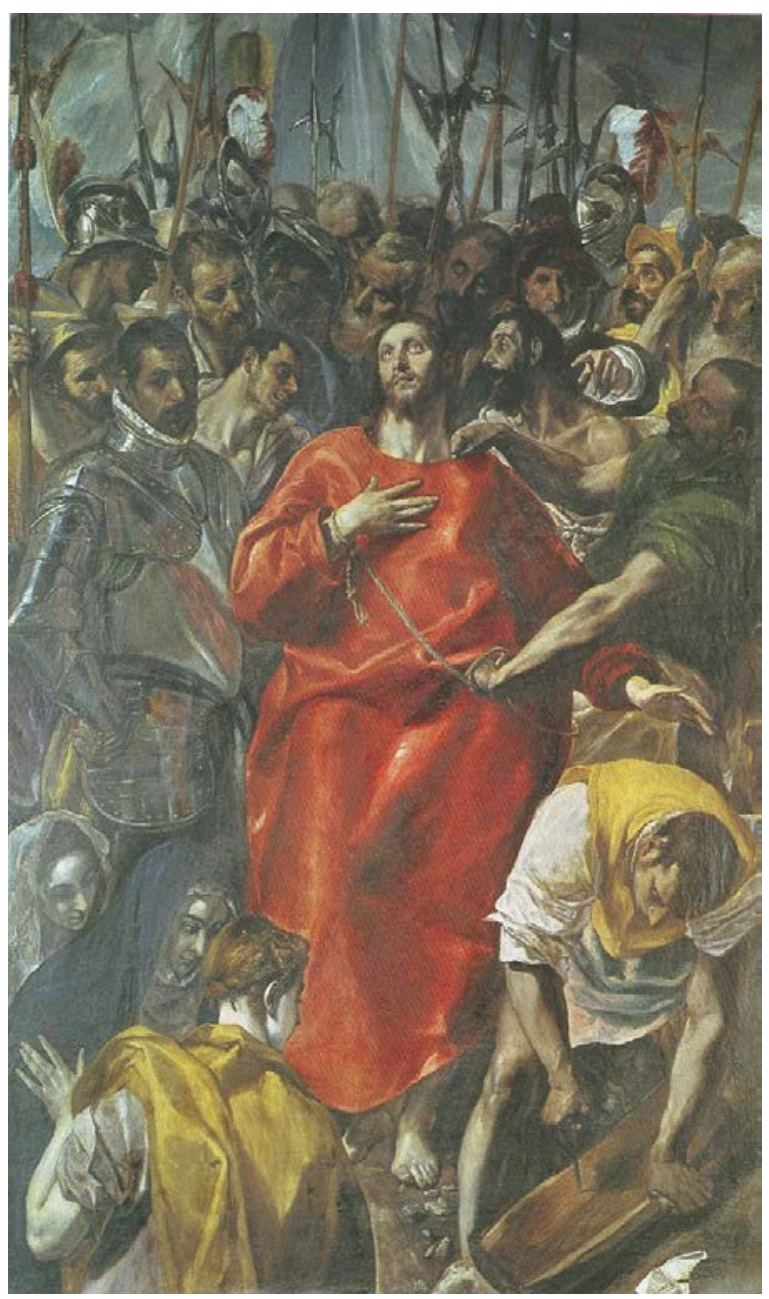

la sugerencia de Azcárate sobre la influencia de San Buenaventura en el tema del Expolio, sumando otros, a esta influencia, textos espirituales de la época del pintor, como los de San Ignacio de Loyola, Santa Teresa de Jesús y algunos más surgidos de la Contrarreforma.

A propósito de todo ello, recordemos cómo en la exposición de El Toledo de El Greco, de 1982, se sugirió algún paralelismo entre El Greco y Juan Correa de Vivar (cf. Mateo Gómez, 1982). Pues bien, contestando a la pregunta de Azcárate de si existió alguna representación del tema, según el texto de San Buenaventura, anterior al de El Greco, podemos responder que varias, pintadas por el toledano Juan Correa de Vivar, treinta años aproximadamente antes de que El Greco comenzara el cuadro para la sacristía de la catedral.

Comenzaremos por un Expolio de Juan Correa de Vivar, que se puede fechar hacia el año 1550, y que proba- blemente estuvo colocado, como cuadro de Estación en el claustro del monasterio cisterciense de San Martín de Valdeiglesias (fig. 8). En los Inventarios de la Desamortización de Mendizábal, se cita en ese monasterio, en el claustro, un cuadro de Estación de "Jesús despojado". Los cuadros de estación colocados en el claustro eran de gran tamaño, así las medidas que se citan son 200×150 $\mathrm{cm}$, no sabemos si son tomadas con marco o sin él, pues es sabida la forma caótica en que se llevaron a cabo estos inventarios y no siempre por las personas adecuadas $^{4}$. Nos atrevemos a identificar este Expolio con el que se expuso de Juan Correa de Vivar, en el año 2008, en el Hotel Ritz de Madrid, por la casa Sotheby's de Londres. La identificación se debe, principalmente, a la presencia de un monje cisterciense, como donante, arrodillado en oración. La diferencia de las medidas podría deberse a que están tomadas sin el marco $(150 \times 123 \mathrm{cms})$. Aparecen las Marías, los soldados con picas, y el cisterciense arrodillado tal vez podríamos identificarlo con el abad que, por aquellos años, dirigía el monasterio, Fray Jerónimo Hurtado, a quien menciona Ponz (1788, tomo II,

Figura 8. Juan Correa de Vivar. El Expolio. En comercio de la casa Sotheby's de Londres en 2008.

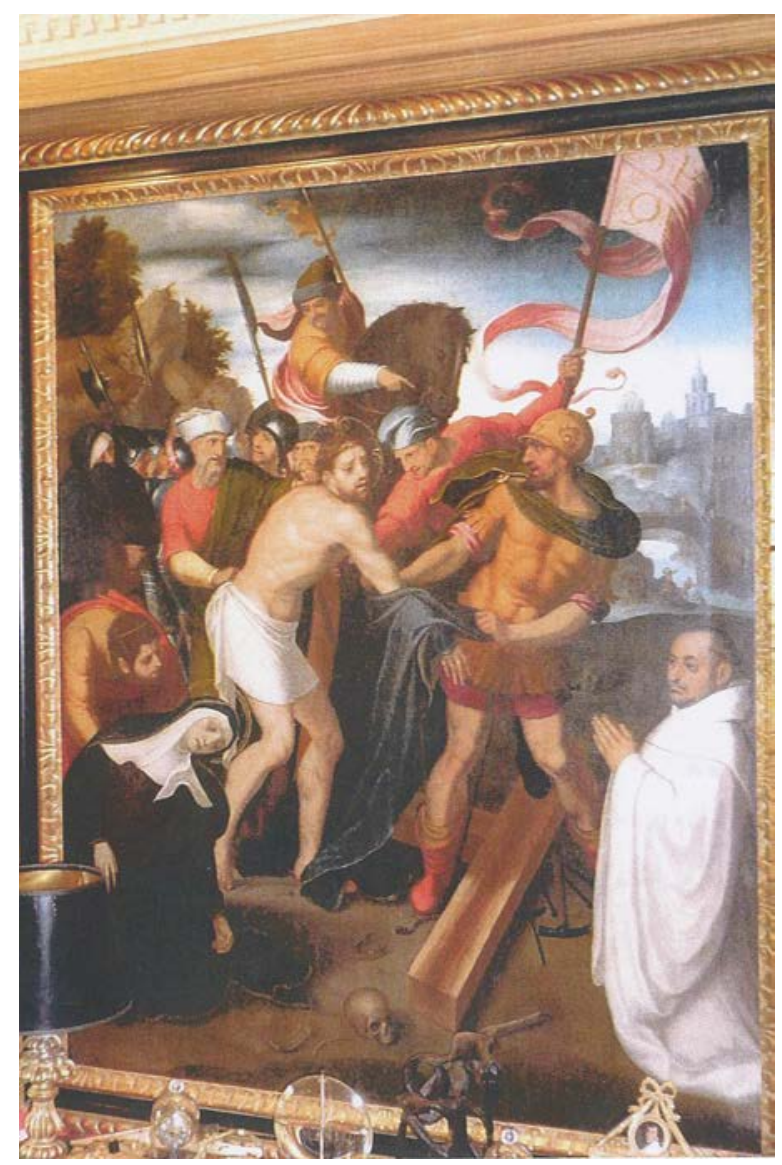


carta VII, párrafo XVIII-XXVIII) como prior del monasterio "cuando Correa pintaba allí, en 1550". Correa de Vivar pudo tener en cuenta para su composición el texto de San Buenaventura, pero al ser la tabla concebida para un monasterio cisterciense, pudo haberse dejado influir por textos vinculados a esta Orden. Entre ellos citaremos las Revelaciones o Meditaciones de Santa Lutgarda, religiosa benedictina belga, amiga de San Bernardo, el fundador de los cistercienses: "Acordaros que fuisteis despojado de vuestras vestiduras y revestido con manto de irrisión", y también por Las oraciones sobre la Pasión de Nuestro Señor Jesucristo, escritas por San Brígida de Suecia, monja cisterciense, que ejerció gran influencia sobre esta Orden: "Acuérdate que fuiste desnudado de tus vestiduras ante los ojos de tu Madre" ${ }^{\prime \prime}$.

Otra tabla con el tema del Expolio pintada por Correa de Vivar y fechada en la década de los sesenta (15601566), fue dada a conocer hace algunos años (fig. 9). Se halla en un pequeño retablo lateral de la iglesia de Almorox (Toledo). En ella la composición adquiere un dinamis-

Figura 9. Juan Correa de Vivar. El Expolio. Iglesia parroquial de Almorox (Toledo).

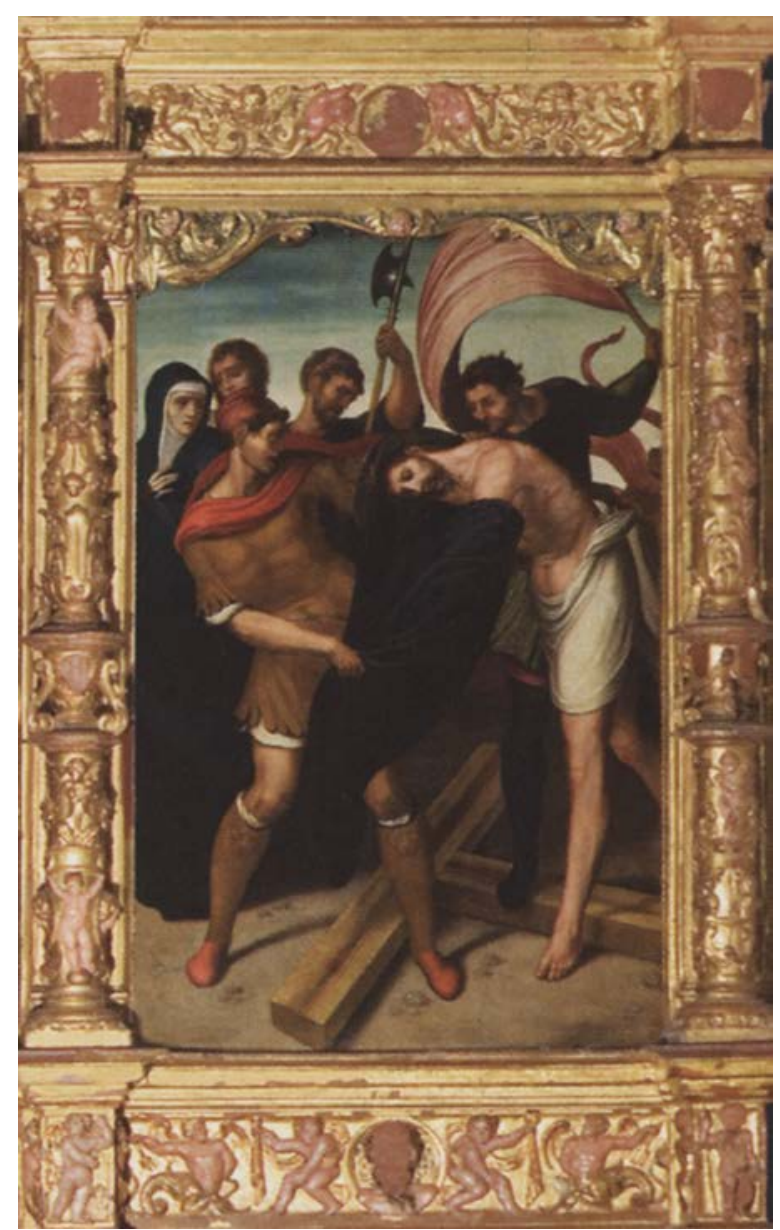

mo manierista de acuerdo con la época en que fue pintada y la Virgen se halla presenciando la escena (cf. Cruz Valdovinos, 1982; Mateo Gómez, 1983, pp. 98-100).

Recientemente hemos localizado otro Expolio (fig. 10), de Juan Correa de Vivar. Se trata de una pequeña tabla, 46x59 cm., que puede fecharse entre 15401545, y ponerse en relación con otras dedicadas a la Pasión de Cristo, inventariadas en el monasterio de San Martín de Valdeiglesias, y que actualmente se haIlan en el Museo de Santa Cruz, de Toledo. La tabla pertenece a la colección cordobesa, García Montañés, y en ella podemos advertir la simplificación que el pintor ha hecho del tema. Las Marías siguen estando presentes y Cristo aparece con las marcas de los latigazos en la espalda. Las dimensiones se corresponden con las de otras tablas del pintor, para retablos sobre la Pasión de Cristo, del citado monasterio cisterciense (cf. Mateo Gómez, 1983, pp. 40-63).

Muy similar al anterior en cuanto a composición, y medidas, $46 \times 47 \mathrm{~cm}$., y fecha de ejecución, es otro Expolio de Correa de Vivar (fig. 11), que, procedente de una colección bilbaína, apareció en el mercado madrileño en 2014. La tablita está cortada en los ángulos superiores, y la escena está muy simplificada: fondo oscuro y, sobre él, la figura de Cristo al que

Figura 10. Juan Correa de Vivar. El Expolio. Colección García Montañés, Córdoba.

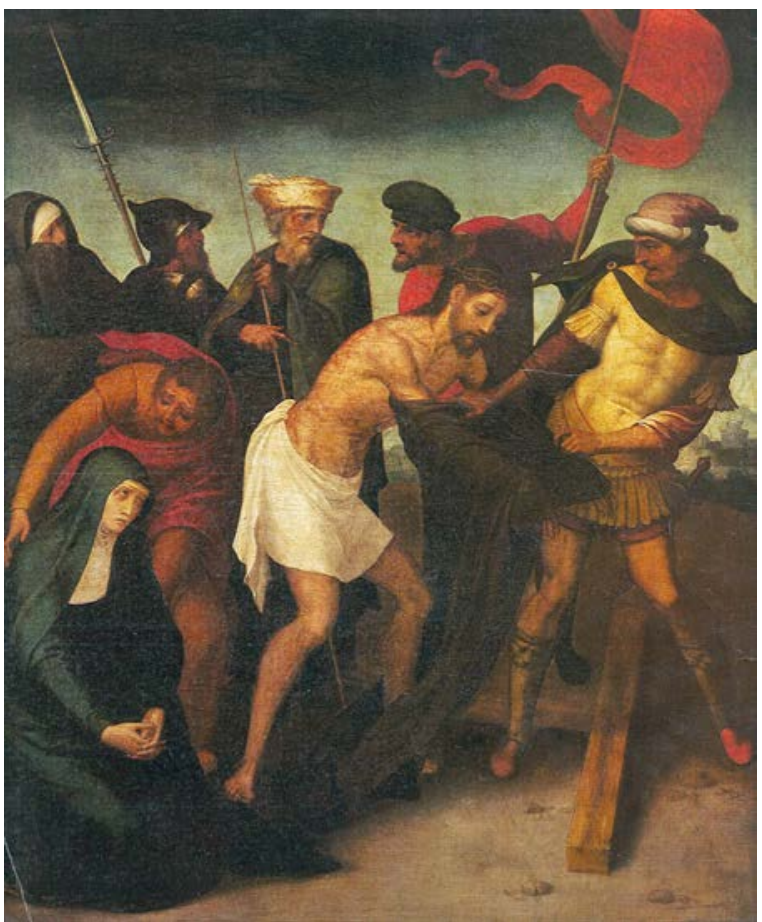


Figura 11. Juan Correa de Vivar. El Expolio. Bilbao, colección privada.

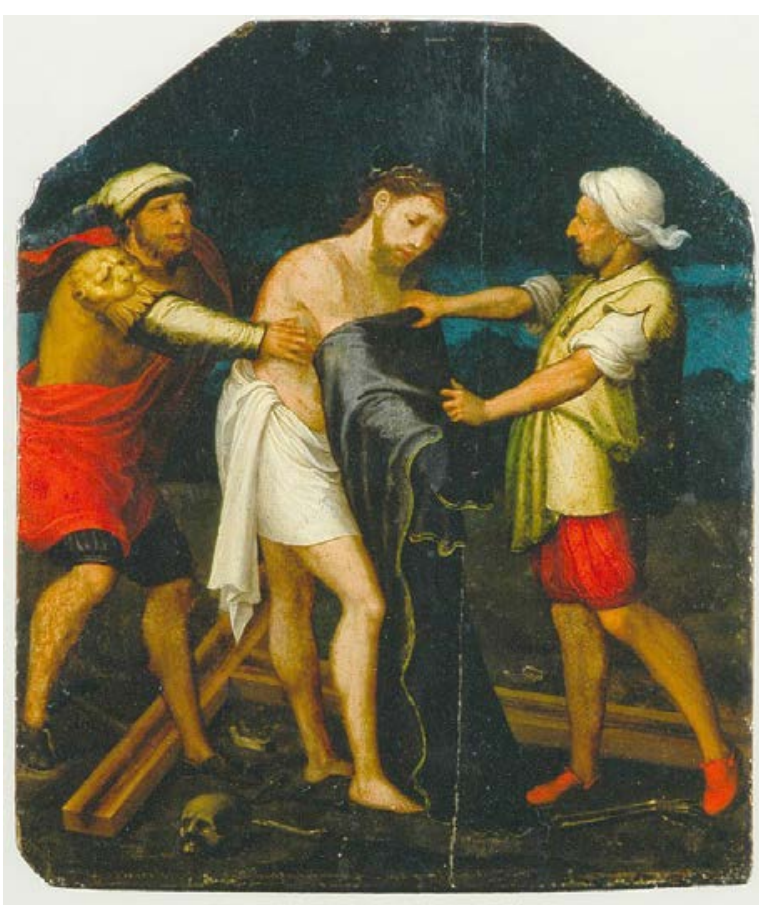

un sayón le quita la túnica y otro le azota. Podría pensarse que se trata de un pequeño boceto para una composición mayor, pero los cortes en los ángulos hacen pensar en una adaptación a un marco, y que hubiera formado parte de un "Via Crucis". Gaya Nuño, en su libro sobre Luis de Morales, sin especificar la fuente de la noticia, dice que el pintor extremeño pintó un "Via Crucis", para Felipe II, que tenía como destino el convento de los Jerónimos de Madrid (Gaya Nuño, 1961, p. 12). Durante tiempo los catálogos han atribuido la obra de Correa a Morales. En nuestra literatura medieval hemos citado los textos de San Buenaventura, Santa Brígida y Santa Lutgarda. A ellos podemos sumar los del Cartujano y los Misterios de la Pasión de Arnoult de Grèban. Ya en el siglo XVI, varios textos anónimos dedican al "Via Crucis" su atención, especialmente uno de 1516, con el título de El retablo de la Vida de Cristo.

Con estos Expolios toledanos, anteriores al de El Greco, creemos que se contesta a la pregunta de Azcárate sobre si existió representación del tema, anterior a El Greco, siguiendo el texto de San Buenaventura. Respecto a la propuesta de Álvarez Lopera de que en el Expolio de El Greco se aúnan dos temas de la Pasión: el Prendimiento y el Escarnio de Cristo, queremos sugerir cómo nos recuerda la composición del cretense al Prendimiento, que Juan Correa de Vivar pintó entre 1548-1550 para el retablo mayor de la iglesia parroquial de Herrera del Duque, en Badajoz (fig. 12), con el fondo de soldados y picas y la figura de Cristo centrando la composición, mientras que un soldado le agarra la túnica por el cuello, del mismo modo que en la obra de El Greco (cf. Tormo, 1902). Es posible que esta lejana influencia de Correa de Vivar y este cierto interés de El Greco por su obra, se debiera a la consideración que el pintor toledano gozó en la ciudad Imperial, y al juicio del Padre Sigüenza por su obra, considerándole "de lo bueno de aquel tiempo" (Sigüenza, 1903, libro I, cap. XIV y libro II, cap. XI ).

Estas consideraciones nos llevan a pensar que El Greco no permaneció en Toledo sin moverse, sino que viajó y pudo recorrer la diócesis toledana, a la que pertenecían San Martín de Valdeiglesias y Badajoz. También es pensable una visita a Portugal, y un conocimiento de la obra de Morales. La "curiosidad" forma parte del hombre humanista, y como escribió don Elías Tormo, el artista no se quedaba en su taller, sino que existió una interrelación de ideas y de escuelas peninsulares (Mateo Gómez y López-Yarto Elizalde, 2005, pp. 70-73).

Figura 12. Juan Correa de Vivar. El Prendimiento de Cristo. Retablo de Herrera del Duque (Badajoz).

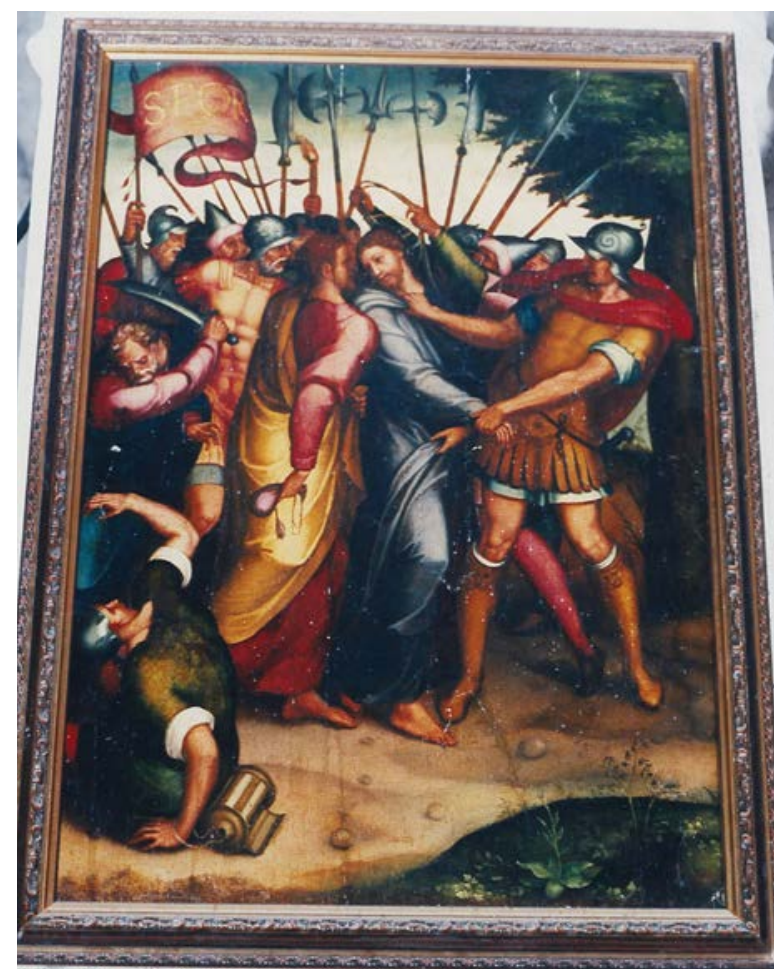


Después de repasar la influencia iconográfica que Juan Correa de Vivar pudo ejercer sobre e El Greco, y de señalar la influencia que ambos pintores tuvieron puntualmente sobre Luis de Velasco, queremos, en esta línea señalar la que dejaron en un pintor flamenco formado en Italia y documentado en Toledo en 1562, a propósito del traspaso que le hizo Luis de Velasco, de la hechura del retablo de San Pedro, para Villar de Pedroso (Cáceres). Se trata de Cornelio Cyaneus (Marías, 1981, p. 319). El estudio de la formación artística de Cyaneus, los motivos que le trajeron a España y el aumento del catálogo de su obra ha sido objeto de estudio en el año 2014 (cf. Mateo Gómez, 2014). Solo unas líneas en relación con El Greco. Si en el retablo de Villar del Pedroso se observa alguna influencia de Luis de Morales en la escena del Encuentro de Cristo y San Pedro en la Vía Apia, y de Correa de Vivar en la de La Resurrección de Tabitha por San Pedro, hemos localizado un San Juan Evangelista, evidentemente influido por modelos de El Greco (figs. 13 y 14), pero dependiente del colorido del Veronés.

Figura 13. Cornelius Cyaneus. San Juan Evangelista. En comercio.

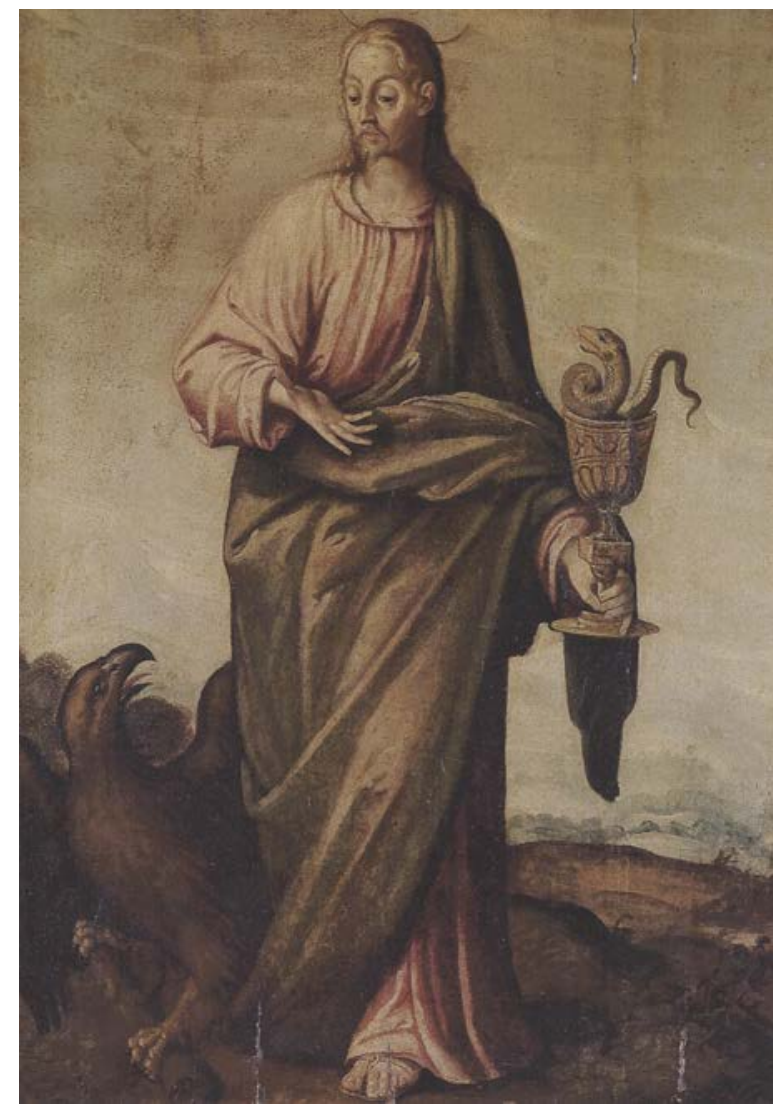

Figura 14. El Greco. San Juan Evangelista. Museo del Prado, Madrid.

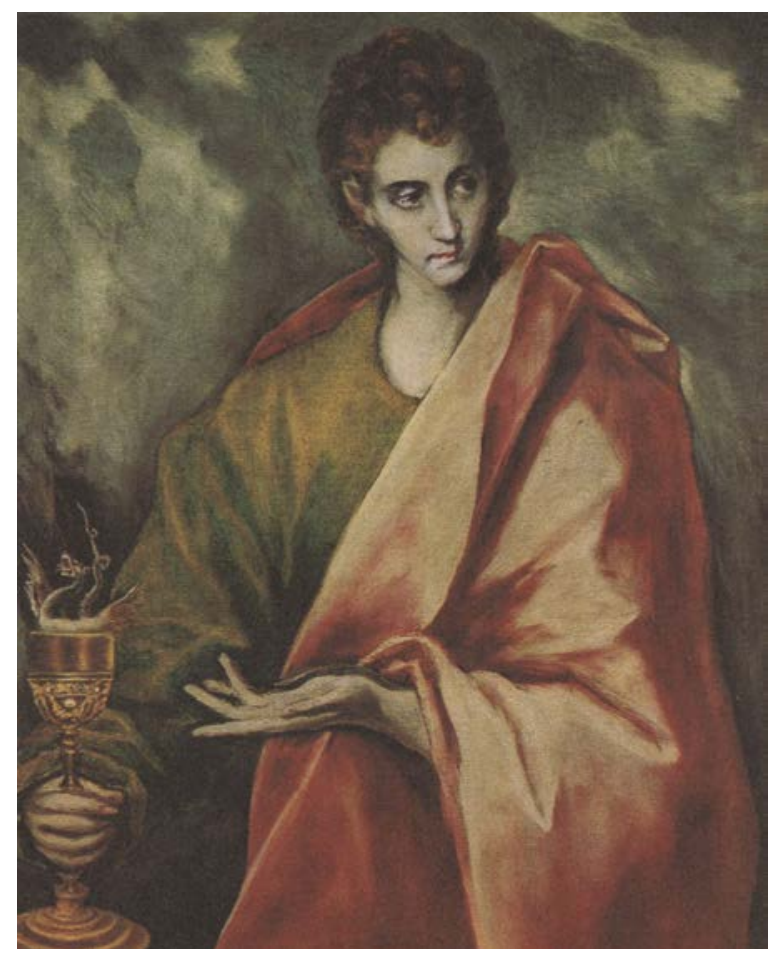

A estos escarceos, de flujos y reflujos, de la obra del cretense, teniendo en cuenta los planteamientos de las exposiciones de 1982, hay que sumar las nuevas perspectivas abiertas y propuestas en las exposiciones de 2014, en el museo de Santa Cruz de Toledo y otros lugares, muy bien enjuiciadas por Ángel Aterido, en un trabajo bajo el título "El Maestro y sus colaboradores” (Aterido, 2014, p. 146). 


\section{NOTAS}

[1] El Comisario de la Exposición ha sido Javier Barón, subrayándose en ella hasta donde los "modernos" han copiado a El Greco. Se echa de menos, quizás, la presencia de algunos abstractos. El tema había sido tratado también por Cossio (1907).

[2] Wethey no cita en la bibliografía el catálogo de Viniegra, donde se reproduce por primera vez el San Roque.

\section{BIBLIOGRAFÍA}

Álvarez Lopera, J. (1985). La Pasión de Cristo en la pintura del Greco. Madrid: Fundación Universitaria Española.

Álvarez Lopera, J. (1995). Las dos Españas y El Greco. En Hadjinicolaou, N. (ed.). El Greco of Crete. Proceedings of the International Symposium held on the occasion of the $450^{\text {th }}$ anniversary of the artist's birth (Iraklion, Crete, 1-5 September 1990). Heraklion: Municipality of Iraklion, pp. 463-479.

Álvarez Lopera, J. (2007). El Greco. Estudio y catálogo. Madrid: Fundación de Apoyo a la Historia del Arte Hispánico.

Aterido, A. (2014). El Maestro y sus colaboradores. Ars Magazine, 24.

Azcárate Ristori, J. M.a (1955). La iconografía de 'El Expolio' del Greco. Archivo Español de Arte, XXVIII, pp. 189-197.

Bandini, B. (1995). El Greco e I'arte italiana contemporánea, 1930-1950.

Barón, J. (2014). El Greco y la pintura moderna. Madrid: Museo Nacional del Prado.

Bellingen, T. van (s.a.). Vita Lutgardis, s.I.

Brown, J., Jordan, W. B., Kagan, R. L. y Pérez Sánchez, A. E. (1982). El Greco de Toledo. Madrid: Dirección General de Bellas Artes, Archivos y Bibliotecas, Fundación Banco Urquijo.

Brown, J. y Pita Andrade, J. M. (eds.). (1984). El Greco: Italy and Spain: proceedings of the symposium held in Toledo, Spain, on 2-4 April 1982. Washington: National Gallery of Art.

Ceán Bermúdez, A. (1800). Diccionario histórico de los más ilustres profesores de las Bellas Artes en España. Madrid: Ibarra.
[3] Todas las ponencias se recogen en Brown y Pita Andrade (1984), un volumen publicado por la National Gallery of Art de Washington.

[4] Papeles en el Archivo de la Real Academia de San Fernando, "De valor de Iglesias", 14 de abril de 1836. Oratorio de Santa Catalina en San Martín de Valdeiglesias.

Cossio, M. B. (1907). El Greco, Velázquez y el arte moderno. Boletín de la Institución Libre de Enseñanza, XXXI, pp. 336346 ; 373-381.

Cruz Valdovinos, J. M. (1982). Retablos inéditos de Juan Correa de Vivar. Archivo Español de Arte, LV, 220, pp. 351-374.

Davies, D. (1982). El Greco and the spiritual Reform. Movements in Spain. En Studies in the History of Art (vol. 13). El Greco: Italy and Spain. Washington: National Gallery of Art, pp. 57-75.

Davies, D. y Elliot, J. H. (2003). El Greco. London: National Gallery.

Foundoulaki, E. (1995). Greco-Cézanne: La filière reperée par Picasso. En Hadjinicolaou, N. (ed.). El Greco of Crete. Proceedings of the International Symposium held on the occasion of the $450^{\text {th }}$ anniversary of the artist's birth (Iraklion, Crete, 1-5 September 1990). Heraklion: Municipality of Iraklion.

Gaya Nuño, J. A. (1961). Luis de Morales. Madrid: Consejo Superior de Investigaciones Científicas.

Hadjinicolaou, N. (ed.). (1995). El Greco of Crete. Proceedings of the International Symposium held on the occasion of the $450^{\text {th }}$ anniversary of the artist's birth (Iraklion, Crete, 1-5 September 1990). Heraklion: Municipality of Iraklion.

Marías, F. (1981). Maestros de la catedral, artistas y artesanos: Datos sobre la pintura toledana de la segunda mitad del siglo XVI (I). Archivo Español de Arte, 215, p. 319.
[5] Bellingen, T. van, Vita Lutgardis, vol. II, 6; Santa Brígida, Oraciones sobre la Pasión de Nuestro Señor Jesucristo. Paredes de Nava, 2003; Condesa de Flavigny, Santa Brígida de Suecia, su vida, sus relaciones y su obra. Valladolid, 1913.

Marías, F. (1989). El largo siglo XVI: los usos artísticos del Renacimiento español. Madrid: Taurus.

Martínez, J. (1866/1988). Discursos practicables del nobilísimo arte de la pintura. Madrid: Akal.

Mateo Gómez, I. (1982). Consideraciones iconográficas sobre la Crucifixión con donantes del Greco para la iglesia de las monjas Jerónimas de Toledo. En Studies in the History of Art (vol. 13). El Greco: Italy and Spain. Washington: National Gallery of Art, pp. 121-123.

Mateo Gómez, I. (1983). Juan Correa de Vivar. Madrid: Consejo Superior de Investigaciones Científicas.

Mateo Gómez, I. (2014). Homenaje al Canónigo de la catedral de Toledo, don Ramón Gonzálvez. Toledo.

Mateo Gómez, I. y López-Yarto Elizalde, A. (2005). Pintura toledana de la segunda mitad del siglo XVI. Madrid: Consejo Superior de Investigaciones Científicas.

Pérez Sánchez, A. E. (1982). Luis de Velasco. En Pérez Sánchez, A. E. (ed.). El Toledo de El Greco. Madrid: Ministerio de Cultura, Dirección General de Bellas Artes, Archivos y Bibliotecas.

Ponz, A. (1788). Viage de España. Madrid: Viuda de Ibarra, Hijos y Compañía.

Rodríguez G. de Ceballos, A. (1982). La repercusión en España del decreto del Concilio de Trento acerca de las imágenes sagradas y las censuras al Greco. En Studies in the History of Art (vol. 13). El Greco: Italy 